\title{
Accessible analytical methodology for assessing workplace contamination of antineoplastic drugs in limited-resource oncology health-care settings
}

\author{
Claudio Müller-Ramírez ${ }^{1 *}$, Katherine Squibb² and Melissa McDiarmid ${ }^{2}$
}

\begin{abstract}
Background: Environmental monitoring of workplaces where antineoplastic drugs are handled constitutes an essential tool to assess occupational exposures among health-care workers. Consequently, availability of simple, sensitive, and affordable analytical methodologies is needed, particularly in health-care settings with limited resources that restrict environmental monitoring studies.

Methods: Previously validated methodologies for simultaneous determination of ifosfamide, cyclophosphamide, and paclitaxel were modified and re-validated in order to create a more sensitive and more accessible liquid chromatography-based analytical method for measuring levels of workplace contamination generated by the handling of antineoplastic drugs in oncology healthcare settings with limited resources.

Results: An HPLC-UV methodology was developed and validated to simultaneously determine ifosfamide, cyclophosphamide, and paclitaxel in field wipe samples collected from oncology health-care settings with limited resources. Solid-phase extraction was incorporated to concentrate analytes and improve their detection and quantification. Adequate limits of detection for ifosfamide $\left(0.02 \mathrm{ng} / \mathrm{cm}^{2}\right)$, cyclophosphamide $\left(0.1 \mathrm{ng} / \mathrm{cm}^{2}\right)$, and paclitaxel $\left(0.03 \mathrm{ng} / \mathrm{cm}^{2}\right)$ were obtained. Also, mean recoveries between 88.7 and $96.2 \%$ were achieved.

Conclusions: The analytical method described here using a more widely available instrumentation provides an excellent alternative to LC-MS when establishing workplace contamination levels produced by the handling of antineoplastic drugs in non-high-income country oncology health-care settings.
\end{abstract}

Keywords: Occupational exposures, Antineoplastic drugs, Environmental monitoring study, Accessible analytical methods

\section{Background}

Antineoplastic drugs (ANDs) have increased in their use given the ongoing rise of number of cancer cases worldwide (Connor and McDiarmid 2006). Consequently, health-care workers are increasingly exposed to these hazardous drugs (HDs) due to work duties. This phenomenon has been studied in North American and European developed countries as well as in Australia for several decades to date (Kopp et al. 2013; Hedmer and Wholfart 2012).

\footnotetext{
* Correspondence: claudiomuller@udec.cl

'Department of Pharmacy, School of Pharmacy, University of Concepcion,

Barrio Universitario S/N, Concepcion 3349001, Chile

Full list of author information is available at the end of the article
}

Important advances in health-care worker protection have been achieved by characterizing these occupational exposures to ANDs, either through environmental or biological monitoring studies (Pampal et al. 2014; Sottani et al. 2007; Brouwers et al. 2007). Occupational safety and health organizations have published safety guidelines for the handling of ANDs as a measure to reduce unnecessary occupational exposures (OSHA 1986; OSHA Directorate of Technical Support 1995, 1999; NIOSH Alert 2004). Nowadays, implementation of these safety guidelines is a common feature among oncology health-care settings around the globe; however, adherence to them is not always a condition that can easily be assessed by simple 
visual inspection in order to establish occupational risks or the efficacy of hazard controls in the workplace (Davis et al. 2011; Connor et al. 2012; McDiarmid et al. 2010).

Non-high-income countries, like their developed peers, have adopted these safety guidelines to protect their health-care workers from unnecessary occupational exposures to ANDs. However, little has been done to assess current extent of surface contamination generated by the handling of these drugs by conducting environmental monitoring studies.

Costs associated with sensitive analytical techniques and methods, such as liquid or gas chromatography coupled to tandem mass spectrometry (GC-MS/MS or LC-MS/MS) are often unaffordable for non-high-income country Ministry of Health laboratories (Zeedijk et al. 2005; Smith et al. 2014).

Assessing workplace environmental contamination by measuring levels of drug residues on work surfaces plays a key role when assessing occupational exposures to ANDs (Friese et al. 2015; Kiffmeyer et al. 2013; Fabrizi et al. 2012; Nussbaumer et al. 2011; Floridia et al. 1999; Maeda and Miwa 2013; Sabattini et al. 2005). Biological monitoring studies, on the other hand, constitute a more accurate estimation of drug uptake and internal occupational exposure. However, these types of studies require even more sensitive instrumentation, which is more expensive and also may require human subject's approval since bodily fluids are needed (Davis et al. 2011; Turci et al. 2003). The methodology described here relates to the use of a less sensitivity analytical tool, but one which is more likely to be available to hospitals or government laboratories in non-high-income countries, and it is still usable for measuring low levels of workplace contamination generated by the manipulation of ANDs in healthcare settings.

\section{Methods}

Previously validated methods for simultaneous determination of five antineoplastic drugs, among them ifosfamide (IF), cyclophosphamide (CP), and paclitaxel (PX), in a single run were modified and re-validated (Larson et al. 2003). Selection criteria for these three HDs were based upon (1) the frequency of their usage (preparation and administration) at the health-care facility where field wipe samples were collected from; (2) previously published works for quantitatively determining ANDs as workplace contaminants (Pretty et al. 2010; Larson et al. 2002); and (3) information contained in the International Agency for Research on Cancer (IARC) monographs for human carcinogenic drugs, as well as in the National Institute for Occupational Safety and Health (NIOSH) Alert for handling HDs (NIOSH Alert 2004; IARC 2015).
Also, specific modifications to the original analytical methodology consisted of (1) replacing a C8 column by a C18 column as the stationary phase because of its more wide availability in analytical laboratories, along with its versatility when separating and analyzing compounds with different physicochemical properties as it is in this case; (2) incorporating an internal standard; (3) slightly varying the gradient elution of the mobile phase in order to decrease the time of analysis; and (4) including a concentration step of wipe samples based on solid-phase extraction to increase the sensitivity of the method, as well as ease of wipe sample storage and transportation. Hexamethylphosphoramide (HMPA) was considered as an adequate internal standard for the proposed method as it was described in some other works (Pretty et al. 2010; De Jonge et al. 2004). Detection of all drugs was carried out at $195 \mathrm{~nm}$.

Table 1 summarizes the chromatographic conditions of the method described here. Chromatographic analyses were made in duplicates and reported as the area ratios of the analytes and that of the internal standard.

\section{Instrumentation}

Analyses of all ANDs were performed on a liquid chromatograph Merck-Hitachi (Japan) equipped with a binary pump L-6200A, an ultraviolet detector L4250, and an interface D-6000. Data acquisition was made through chromatography data station manager HSM. Surface-wipe samples were extracted by using a negative pressure Burdick and Jackson SPE manifold (CA, USA). As for the evaporation procedure, an Organomation Mayer II-2 analytical evaporator (MA, USA) was employed. Also, a Mettler Toledo $\mathrm{pH}$ meter (OH, USA) was utilized to adjust $10 \mathrm{mM}$ phosphate buffer to $\mathrm{pH}$ 6.0.

Table 1 Experimental chromatographic conditions for the analysis of ifosfamide, cyclophosphamide, and paclitaxel in workplace wipe samples

\begin{tabular}{|c|c|}
\hline $\begin{array}{l}\text { Chromatography } \\
\text { component }\end{array}$ & Chromatographic characteristics \\
\hline Stationary phase & Waters Symmetry ${ }^{\oplus} \mathrm{C} 18,5 \mu \mathrm{m}, 4.6 \times 150 \mathrm{~mm}$ column \\
\hline \multirow[t]{5}{*}{ Mobile phase } & Acetonitrile:10 mM phosphate buffer pH 6 \\
\hline & 0-9.9 min, $25 \%$ A, $75 \%$ B \\
\hline & $10-20 \min , 60 \%$ A, $40 \%$ B \\
\hline & $20.1-25 \min , 25 \% \mathrm{~A}, 75 \% \mathrm{~B}$ \\
\hline & $\begin{array}{l}A=100 \% \mathrm{ACN}, \mathrm{B}=100 \% \text { buffer }\left(\mathrm{KH}_{2} \mathrm{PO}_{4} 1.1936 \mathrm{~g} \text {, }\right. \\
\mathrm{K}_{2} \mathrm{HPO}_{4} 0.2143 \mathrm{~g} \text {, dissolve in } 1 \mathrm{~L} \text { of } \mathrm{DI} \text { water, } \\
\text { adjust at pH } 6 \text { with phosphoric acid) }\end{array}$ \\
\hline Flow rate & $1.0 \mathrm{~mL} / \mathrm{min}$ \\
\hline $\begin{array}{l}\text { Detection } \\
\text { wavelength }\end{array}$ & $195 \mathrm{~nm}$ \\
\hline Injection volume & $20 \mu \mathrm{L}$ \\
\hline
\end{tabular}




\section{Reagents}

Stock solutions of the analytes under study, positive and negative control solutions, as well as the mobile phase were prepared using methanol and acetonitrile Lichrosolv ${ }^{\circ}$, along with ortho-phosphoric acid, monobasic and dibasic potassium phosphate (Merck, Darmstadt, Germany), and submicron-filtered water (Fisher Scientific). Ethylacetate Suprasolv ${ }^{\oplus}$ was used to elute analytes from solid-phase extraction cartridges.

Ifosfamide, cyclophosphamide, paclitaxel, and hexamethylphosphoramide HPLC certified standards (purity >98\%) were purchased from Sigma-Aldrich (St. Louis, MO, USA).

\section{Preparation of stock and standard solutions}

Stock solutions of each antineoplastic drug, including that of the internal standard, were prepared in methanol at $400 \mu \mathrm{g} / \mathrm{mL}$. Thus, standard solutions were elaborated by diluting known aliquots of each stock solution with a mixture of methanol, acetonitrile, and $10 \mathrm{mM}$ phosphate buffer pH $6(25: 10: 65 v / v)$ matching a desorbing solvent used to collect field wipe samples (Larson et al. 2002). Stock solutions were frozen at $-20{ }^{\circ} \mathrm{C}$ and standard solutions refrigerated at $5{ }^{\circ} \mathrm{C}$. The frozen stock solutions were stable for 2 months, and the refrigerated standard solutions were stable for 3 weeks (data not shown).

\section{Linearity}

Linear responses of the instrument were tested by running calibration standard solutions containing IF, CP, and PX up to $30 \mu \mathrm{g} / \mathrm{mL}$. These compounds were analyzed separately and in mixture. The internal standard HMPA was added at $20 \mu \mathrm{g} / \mathrm{mL}$ to each solution. Recoveries of $\pm 10 \%$ of the nominal concentration levels were accepted.

\section{Sensitivity: detection and quantification limits}

Three low-level standard and blank solutions were prepared and analyzed on three different days to build linear regression plots that were used to estimate both the limit of detection (LOD) and limit of quantification (LOQ) according to

$$
\begin{aligned}
& \mathrm{LOD}=(3.3 s) / b \\
& \mathrm{LOQ}=(10 s) / b
\end{aligned}
$$

$s$ corresponds to the standard deviation of the intercept and $b$ to the slope of the linear regression plot (International Conference on Harmonization of Technical Requirements for Registration of pharmaceuticals for $\mathrm{Hu}$ man Use: Validation on Analytical Procedures, Text and Methodology, Q2(R1), 1996). All these values were first calculated as nanograms per milliliter $(\mathrm{ng} / \mathrm{mL})$, and then converted into nanograms per square centimeter $\left(\mathrm{ng} / \mathrm{cm}^{2}\right)$ units as can be seen in the "Sample processing" section, Eq. 3.

\section{Wipe media and surface sampling recovery}

The selected methodology for performing and processing environmental wipe samples was taken from the work of Larson et al. (2002, 2003) and Pretty et al. (2010). Additionally, solid-phase extraction (SPE) performed on Hypersep ${ }^{\bullet}$ C18 cartridges 200 mg/3 mL (Thermo Scientific, Waltham, MA) for sample enrichment was incorporated in order to enable detection of low concentration levels of all three ANDs in field wipe samples.

Two filter papers (Whatman 42, $55 \mathrm{~mm}$ diameter) previously wetted with $250 \mu \mathrm{L}$ of the desorbing solvent (methanol: acetonitrile: $10 \mathrm{mM}$ potassium phosphate buffer $\mathrm{pH} 6,25: 10: 65 v / v)$ were used to wipe a templated area of $400 \mathrm{~cm}^{2}$. The desorbing solvent had been found to efficiently extract and provide acceptable wipe sample recoveries of all three ANDs under study in the current work (Pretty et al. 2010).

Extraction efficiency from wipe media was tested by preparing control standard solutions as follows: two filter papers were wetted with $250 \mu \mathrm{L}$ of the desorbing solvent and spiked with appropriate aliquots of antineoplastic drug stock solutions at specific concentrations assuming quantitative extraction. The wipes were then placed together in a $125-\mathrm{mL}$ wide mouth polypropylene screw-cap Nalgene ${ }^{\bullet}$ jar to be processed and analyzed as it is described in the sample processing below.

\section{Sample processing}

The internal standard was added at $20 \mu \mathrm{g} / \mathrm{mL}$ to each jar, along with the necessary volume of desorbing solvent to complete $10 \mathrm{~mL}$, considering liquid is already present in the filter papers. Extra precaution was taken to eliminate any bubbles of air located between the filter papers. The jars were then sonicated for $10 \mathrm{~min}$ with the liquid in the jars completely immersed below water level to assure homogeneity. After sonication, all droplets generated by condensation on the inner wall of the jars were placed back together into the sonicated liquid. Filtration of the supernatant $(8-9 \mathrm{~mL})$ was performed with a $10-\mathrm{mL}$ plastic syringe connected to a $0.22-\mu \mathrm{m}$ syringe-driven filter $\left(\right.$ Millex $\left.^{\oplus}\right)$ and received in a $15-\mathrm{mL}$ glass tube. Afterwards, a 2-mL aliquot of the filtered solution was loaded and dried under vacuum for $5 \mathrm{~min}$ on a preconditioned Hyperserp C18 $200 \mathrm{mg} / 3 \mathrm{~mL}$ Thermo Scientific cartridge with $3 \mathrm{~mL}$ of methanol and $3 \mathrm{~mL}$ of deionized water. Then, the analytes of interest retained on the cartridge were eluted with $2 \mathrm{~mL}$ of ethyl acetate, which was completely evaporated under nitrogen at room temperature $\left(20^{\circ} \mathrm{C}\right)$. The residue was finally reconstituted with $200 \mu \mathrm{L}$ of the desorbing solvent.

All wipe samples were obtained from an area of $400 \mathrm{~cm}^{2}$. Concentration units $(\mathrm{ng} / \mathrm{mL})$ were converted into mass/ area units as follows: 


$$
[10 \mathrm{~mL}(X \mathrm{ng} / \mathrm{mL})] / 400 \mathrm{~cm}^{2}=0.025 X \mathrm{ng} / \mathrm{cm}^{2}
$$

Thus, a concentration value of $X \mathrm{ng} / \mathrm{mL}$ corresponds to 0.025 of the value as mass/area $\left(\mathrm{ng} / \mathrm{cm}^{2}\right)$.

\section{Wipe sample enrichment (concentration) study}

Three levels of concentrated and non-concentrated spiked wipe samples containing IF, CP, and PX at 5, 10, and $15 \mu \mathrm{g} / \mathrm{mL}$ and HMPA at $20 \mu \mathrm{g} / \mathrm{mL}$ were prepared on three different days. Enrichment factors were calculated as the recovery ratios of concentrated and nonconcentrated spiked wipe sample levels.

\section{Storage stability study of wipe samples}

Two spiked wipe sample sets were prepared as quality control subjects to be studied under storage conditions. These sets consisted of three known concentration levels of spiked wipe samples within the linear range of the method containing IF, CP, and PX at 5.0, 10.0, and $15.0 \mu \mathrm{g} / \mathrm{mL}$ and HMPA at $20 \mu \mathrm{g} / \mathrm{mL}$; the first set was frozen at $-20{ }^{\circ} \mathrm{C}$ with no SPE procedure involved, and the second was kept at room temperature $\left(20^{\circ} \mathrm{C}\right)$ on the SPE cartridges protected from light. Both sets of spiked wipe samples remained under these storage conditions for 2 months. All these samples were then processed as described above and quantified in terms of the amount of each drug recovered after the 2-month storage period. Additionally, a $t$ test for paired samples $(N=27)$ was run to check for statistical difference of mean recoveries at the two storage conditions since the data appeared normally distributed (SYSTAT 12 for Windows, Version 12.02.00).

\section{Recovery, repeatability, and reproducibility studies of wipe samples}

Two sets of quality control wipe samples were used to cover the linear range proposed in the analytical method: (1) laboratory control samples (LCS) were identically prepared as those calibration standard solutions (see "Linearity" subsection) but at different concentration levels for each drug (i.e., 3.5, 6.0, 8.0, 9.5, and $15.0 \mu \mathrm{g} / \mathrm{mL}$ ). The internal standard was added at $20 \mu \mathrm{g} / \mathrm{mL}$, and no SPE procedure was involved at this stage. (2) Performance quality control (PQC)-spiked wipe samples with and without SPE procedure were elaborated by adding known amounts of IF, CP, and PX (i.e., 4.0, 5.5, 7.0, 13.0, and
$15.0 \mu \mathrm{g} / \mathrm{mL}$ and HMPA at $20 \mu \mathrm{g} / \mathrm{mL}$ ) on filter papers assuming quantitative extraction recovery. Mean recoveries (accuracy) of each drug between 80 and $120 \%$ of the nominal concentration level were considered acceptable for analytical purposes (FDA Guidance for Industry and Bioanalytical Method 2001).

Similar to recovery, repeatability and reproducibility (precision) were determined by analyzing PQC wipe samples on 1 and 5 days, respectively. Relative standard deviation values of less than $2 \%$ were considered suitable for analytical purposes (FDA Guidance for Industry and Bioanalytical Method 2001).

\section{Results}

Linearity

Linear responses were observed up to $15 \mu \mathrm{g} / \mathrm{mL}$, accepting this value as the upper limit of the dynamic linear range for IF, CP, and PX. Table 2 shows concentration levels, linear regression equations, and coefficients of determination for all ANDs under study. Five consecutive injections of each set of calibration solutions were analyzed. Thus, coefficients of determination $\left(r^{2}\right)$ equal or greater than 0.990 were considered adequate for the proposed method.

Figure 1 shows representative chromatograms of a blank solution, a standard solution, a spiked wipe sample solution, and a field wipe sample containing ANDs along with the internal standard HMPA. No matrix interferences or background signals were observed at the analytes' retention times.

\section{Sensitivity}

Limits of detection and quantification were calculated for IF, CP, and PX as described above and are summarized in Table 3. These values provided appropriate sensitivity when establishing levels of workplace contamination produced by the handling of ANDs.

\section{Wipe sample enrichment study}

Sample enrichment factors, gained through the concentration step on SPE cartridges, were close to ten (see Table 4). Therefore, this value was considered when analyzing field wipe samples.

Table 2 Chromatographic method linearity parameters

\begin{tabular}{llll}
\hline Antineoplastic drug & Concentration level $(\mu \mathrm{g} / \mathrm{mL})$ & Linear regression equation & Coefficient of determination $\left(r^{2}\right)$ \\
\hline Ifosfamide & $3,5,7.5,10,12.5,15$ & $y=2227 x-0.4$ & 0.9934 \\
Cyclophosphamide & $2.5,5,7.5,10,12.5,15$ & $y=2211 x-1249$ & 0.9941 \\
Paclitaxel & $1,3,6,9,12,15$ & $y=86,543 x-25,469$ & 0.9969 \\
Hexamethylphosphoramide (IS) & 20 & - & - \\
\hline
\end{tabular}



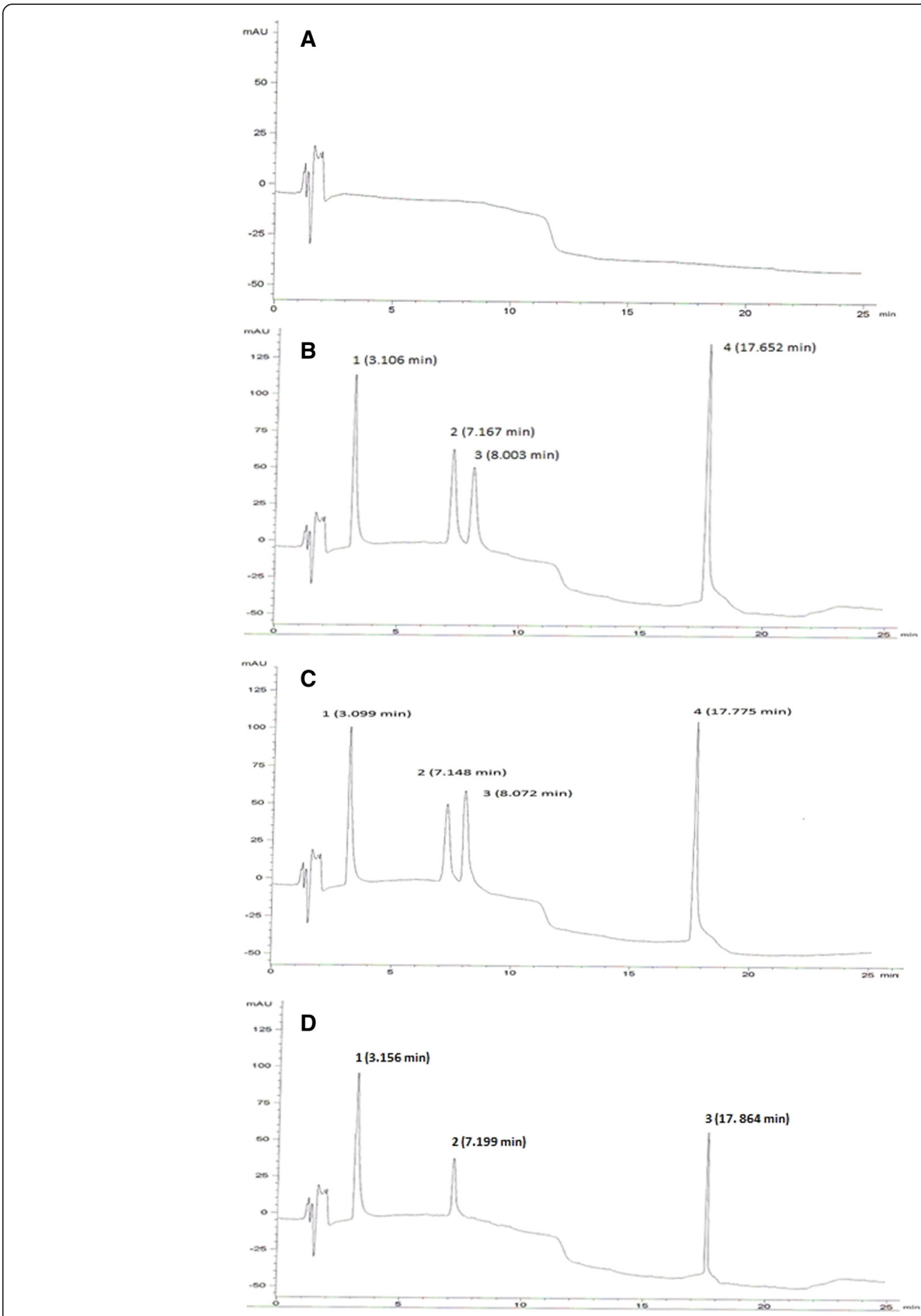

Fig. 1 Representative chromatograms of ifosfamide, cyclophosphamide, paclitaxel, and the internal standard hexamethylphosphoramide. a A blank solution. b A standard solution containing (1) hexamethylphosphoramide (20 $\mu \mathrm{g} / \mathrm{mL})$, (2) ifosfamide and (3) cyclophosphamide (10 $\mu \mathrm{g} / \mathrm{mL})$, and (4) paclitaxel (9 $\mathrm{mg} / \mathrm{mL})$. c A spiked wipe sample containing (1) hexamethylphosphoramide ( $20 \mu \mathrm{g} / \mathrm{mL})$, (2) ifosfamide (4 $\mu \mathrm{g} / \mathrm{mL})$, (3) cyclophosphamide $(5 \mu \mathrm{g} / \mathrm{mL})$, and (4) paclitaxel $(7 \mu \mathrm{g} / \mathrm{mL})$. d A field wipe sample containing (1) hexamethylphosphoramide $(20 \mu \mathrm{g} / \mathrm{mL}),(2)$ ifosfamide $(2.5 \mu \mathrm{g} / \mathrm{mL})$, and (3) paclitaxel $(4.8 \mu \mathrm{g} / \mathrm{mL})$. Flow rate $1.0 \mathrm{~mL} / \mathrm{min}$, gradient elution (see Table 1) and detection at $195 \mathrm{~nm}$ 
Table 3 Detection and quantification limits for ifosfamide, cyclophosphamide, and paclitaxel

\begin{tabular}{lllllll}
\hline & \multicolumn{5}{l}{ Limit of detection } & \multicolumn{3}{l}{ Limit of quantification } \\
\hline Antineoplastic drug & $\begin{array}{l}\text { Instrumental } \\
(\mathrm{ng} / \mathrm{mL})^{\mathrm{a}}\end{array}$ & $\begin{array}{l}\text { Wipe media } \\
\left(\mathrm{ng} / \mathrm{cm}^{2}\right)^{\mathrm{b}}\end{array}$ & $\begin{array}{l}\text { Concentrated wipe media } \\
\left(\mathrm{ng} / \mathrm{cm}^{2}\right)^{c}\end{array}$ & $\begin{array}{l}\text { Instrumental } \\
(\mathrm{ng} / \mathrm{mL})^{\mathrm{a}}\end{array}$ & $\begin{array}{l}\text { Wipe media } \\
\left(\mathrm{ng} / \mathrm{cm}^{2}\right)^{\mathrm{b}}\end{array}$ & $\begin{array}{l}\text { Concentrated wipe media } \\
\left(\mathrm{ng} / \mathrm{cm}^{2}\right)^{c}\end{array}$ \\
Ifosfamide & 10 & 0.2 & 0.02 & 32 & 0.8 & 0.08 \\
Cyclophosphamide & 41 & 1 & 0.1 & 124 & 3 & 0.3 \\
Paclitaxel & 13 & 0.3 & 0.03 & 39 & 1 & 0.1 \\
\hline
\end{tabular}

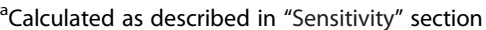

${ }^{b}$ Based on the $400-\mathrm{cm}^{2}$ wipe area with extraction into $10 \mathrm{~mL}$, no further concentration steps

'Based on the $400-\mathrm{cm}^{2}$ wipe area with extraction into $10 \mathrm{~mL}$, tenfold further concentration step

\section{Storage stability study of wipe samples}

No significant decrease of recovery was detected for the spiked wipe samples under specific storage conditions during the 2-month period as it can be seen in Table 5 (96.4 to $99.3 \%$ ). The $t$ test for paired samples showed that there was no evidence that the recovery means were different $(p=0.738)$, suggesting that both storage conditions are equally effective in retaining analytes' chemical stability up to 2 months.

\section{Recovery, repeatability, and reproducibility studies of wipe samples}

Table 6 summarizes the extraction recoveries (accuracy) for the laboratory control samples and performance quality control spiked wipe samples. Table 7 shows repeatability and reproducibility (precision) of the method.

In general, recovery (accuracy) and precision (repeatability and reproducibility) values were in accordance with the analytical purposes of the method, 80-120\% of nominal concentration and $\leq 2 \%$ of relative standard deviation, respectively.

\section{Discussion}

Scarcity of documented occupational exposures to antineoplastic drugs in non-high-income countries makes it difficult to assess occupational risks for workers who directly or indirectly participate in the handling of ANDs. To date, environmental monitoring studies conducted in health-care settings with limited resources are uncommon; therefore, quantitative information about workplace contamination levels produced by the handling of HDs is unknown. Similarly, medical surveillance programs contribute to partially assess occupational risks associated with exposures to HDs by gathering qualitative information from workers (World Health Organization/Pan American Health Organization 2013). Nevertheless, availability of quantitative information is more desirable when aiming to protect workers from occupational exposures in the workplace, especially if dealing with ANDs.

Specific modifications of the original analytical methodology resulted in valuable improvements. Consequently, the proposed method was able to reduce the total time of analysis to $25 \mathrm{~min}$ for separating and measuring all three drugs contained in environmental wipe samples, increasing the throughput when compared to the original chromatographic method (65 $\mathrm{min}$ ), this is due to the use of the C18 column instead of the C8 stationary phase, along with the slight variation of the gradient elution of the mobile phase. Ifosfamide and cyclophosphamide are hydrophilic compounds whereas paclitaxel presents hydrophobic properties.

Table 4 Wipe sample enrichment factors for ifosfamide, cyclophosphamide, and paclitaxel

\begin{tabular}{|c|c|c|c|}
\hline $\begin{array}{l}\text { Nominal concentration } \\
(\mu \mathrm{g} / \mathrm{mL})\end{array}$ & $\begin{array}{l}\text { Recovery of concentrated spiked } \\
\text { wipe samples (mean } \pm \text { SD \%) }\end{array}$ & $\begin{array}{l}\text { Recovery of non-concentrated spiked } \\
\text { wipe samples (mean } \pm \text { SD \%) }\end{array}$ & $\begin{array}{l}\text { Ratio concentrated non-concentrated } \\
\text { spiked wipe samples }\end{array}$ \\
\hline \multicolumn{4}{|l|}{ Ifosfamide } \\
\hline 5 & $1018.0 \pm 0.45$ & $92.0 \pm 0.87$ & 11.1 \\
\hline 10 & $907.0 \pm 1.2$ & $111.0 \pm 2.4$ & 8.2 \\
\hline 15 & $1042.0 \pm 1.9$ & $105.3 \pm 1.7$ & 9.9 \\
\hline \multicolumn{4}{|l|}{ Cyclophosphamide } \\
\hline 5 & $896.0 \pm 1.3$ & $108.0 \pm 0.54$ & 8.3 \\
\hline 10 & $982.0 \pm 0.32$ & $96.0 \pm 0.71$ & 10.2 \\
\hline 15 & $1009.3 \pm 1.8$ & $119.3 \pm 1.2$ & 8.5 \\
\hline \multicolumn{4}{|l|}{ Paclitaxel } \\
\hline 5 & $985.0 \pm 1.4$ & $98.0 \pm 0.48$ & 10.0 \\
\hline 10 & $957.0 \pm 2.7$ & $115.0 \pm 1.8$ & 8.3 \\
\hline 15 & $988.7 \pm 0.12$ & $105.3 \pm 0.69$ & 9.4 \\
\hline
\end{tabular}


Table 5 Comparative recovery percentage of spiked wipe samples at varied storage conditions: (1) $-20^{\circ} \mathrm{C}$ and (2) on SPE cartridges at room temperature $\left(20^{\circ} \mathrm{C}\right)$ and protected from light

\begin{tabular}{llll}
\hline & Wipe samples stored at $-20^{\circ} \mathrm{C}$ & $\begin{array}{l}\text { Wipe samples stored on SPE cartridges } \\
\text { at room temperature }\left(20^{\circ} \mathrm{C}\right)\end{array}$ & Paired $t$ test $p$ value \\
\hline Antineoplastic drug & Mean recovery \pm SD \% & Mean recovery \pm SD $\%$ & 0.738 \\
Ifosfamide & $96.6 \pm 9.9$ & $97.3 \pm 4.1$ & \\
Cyclophosphamide & $97.1 \pm 6.6$ & $95.1 \pm 4.4$ & $99.3 \pm 8.8$ \\
Paclitaxel & $96.4 \pm 6.3$ & 9.3 & \\
\hline
\end{tabular}

$N=27$

${ }^{\mathrm{a}} 95 \%$ confidence interval

Also, the incorporation of an internal standard contributed to better recovery percentages (accuracy 80-120\%) and repeatability and reproducibility (precision $\leq 2 \%$ of RSD) when processing and extracting field wipe samples.

Furthermore, solid-phase extraction for sample enrichment was successfully performed achieving tenfold concentration factors. In accordance, the method was able to detect concentration levels as low as $0.02 \mathrm{ng} / \mathrm{cm}^{2}$ (i.e., IF $0.02 \mathrm{ng} / \mathrm{cm}^{2}$, CP $0.1 \mathrm{ng} / \mathrm{cm}^{2}$, and PX $0.03 \mathrm{ng} / \mathrm{cm}^{2}$ ), which are comparable to those provided by LC-MS and GC-MS methods. For example, limits of detection from varied environmental monitoring studies reported in the work of Turci et al. (2003) ranged from 0.01 to $0.02 \mathrm{ng} / \mathrm{cm}^{2}$ for CP (GC-MS), $0.01 \mathrm{ng} / \mathrm{cm}^{2}$ for IF (LC-MS), and $0.1 \mathrm{ng} / \mathrm{cm}^{2}$ for PX (LC-MS). Similarly, Pretty et al. (2010) described these values for the same drugs (i.e., IF and CP $0.1 \mathrm{ng} / \mathrm{cm}^{2}$ and PX $0.07 \mathrm{ng} / \mathrm{cm}^{2}$ ). At this time, the study did not include any LC-MS test for comparing sensitivity levels.

As for LOQs, there are fewer articles involving environmental monitoring studies where these values were reported apart from LODs (Berruyer et al. 2015; Guillemette et al. 2014; Bobin-Dubigeon et al. 2013; Castiglia et al. 2008; Acampora et al. 2005; Hedmer et al. 2005). From an analytical stand point, it is important to differentiate between reporting environmental contamination levels as above LOD and LOQ. In theory, samples above LOQ should be reported as those that are accurately

Table 6 Wipe sample extraction recoveries (accuracy)

\begin{tabular}{llll}
\hline Antineoplastic drug & $\begin{array}{l}\text { Type of } \\
\text { sample }\end{array}$ & $\begin{array}{l}\text { Recovery } \\
\text { interval (\%) }\end{array}$ & $\begin{array}{l}\text { Mean recovery } \\
\text { and (RSD) (\%) }\end{array}$ \\
\hline Ifosfamide & LCS & $90.5-111.8$ & $98.8(5.6)$ \\
& PQC & $85.2-115.0$ & $95.7(8.1)$ \\
Cyclophosphamide & PQC + SPE & $80.3-107.9$ & $96.2(10.9)$ \\
& LCS & $93.0-104.6$ & $98.5(7.9)$ \\
Paclitaxel & PQC & $91.9-106.7$ & $94.9(8.5)$ \\
& LCS & $87.3-103.8$ & $93.5(12.8)$ \\
& PQC & $89.3-115.6$ & $108.2(10.1)$ \\
& PQC + SPE & $79.4-108.8$ & $92.7(9.8)$ \\
\hline
\end{tabular}

LCS laboratory control sample, $P Q C$ performance quality control sample, $S P E$ solid-phase extraction, $R S D$ relative standard deviation quantifiable by any validated analytical method (Connor and McDiarmid 2006; FDA Guidance for Industry and Bioanalytical Method 2001). However, from an occupational safety scenario, any level above LOD should be reported as such, given the importance of detecting traces of these highly toxic ANDs in the workplace when aiming to reduce unnecessary occupational exposures among health-care workers.

Additionally, SPE cartridges ease sample storage in the event that samples might not be analyzed immediately or in case that specimens need to be shipped to other research facilities for a more complete analysis, thus providing a safer way to handle wipe samples containing HDs during transportation.

\section{Conclusions}

A more accessible liquid chromatography method was validated to quantitatively determine ifosfamide, cyclophosphamide, and paclitaxel in workplace wipe samples collected from oncology health-care settings. The analytical method was demonstrated to have adequate validation parameters, including linearity, sensitivity, accuracy, and precision. These analytical features make the proposed

Table 7 Wipe sample extraction repeatability and reproducibility (precision)

\begin{tabular}{llll}
\hline Antineoplastic drug & $\begin{array}{l}\text { Type of } \\
\text { sample }\end{array}$ & \multicolumn{2}{l}{ Relative standard deviation (\%) } \\
\cline { 3 - 4 } & LCS & 1.6 & 1.3 \\
\hline Ifosfamide-day ${ }^{\mathrm{a}}$ & 2.0 \\
& PQC & 1.9 & $2.1^{c}$ \\
& PQC + SPE & 1.7 & 1.9 \\
Cyclophosphamide & LCS & 1.4 & 1.8 \\
& PQC & $2.2^{c}$ & 1.7 \\
Paclitaxel & PQC + SPE & 1.5 & 1.8 \\
& LCS & 1.5 & 2.0 \\
& PQC & 1.9 & $2.3^{c}$ \\
\hline
\end{tabular}

LCS laboratory control sample, $P Q C$ performance quality control sample, SPE solid-phase extraction

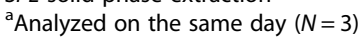

${ }^{\mathrm{b}}$ Analyzed on five different days $(N=15)$

'Values out of acceptance criterion 
analytical method an excellent alternative to be considered when assessment of occupational risks associated with antineoplastic drug exposures among health-care workers is required, particularly in non-high-income countries when the state-of-the-art analytical technology may be unavailable or unaffordable for health-care settings or Ministries of Health laboratories.

The more accessible chromatographic method was successfully applied to the evaluation of workplace contamination generated by the handling of antineoplastic drugs in oncology health-care settings with limited resources (data not shown).

\section{Competing interests}

The authors declare that they have no competing interests.

\section{Authors' contributions}

CMR as the main author performed the study design, carried out all experiments, and participated of data interpretation and manuscript elaboration. KS contributed to the data analysis and manuscript preparation. MM articulated the realization of the research and participated of the manuscript's elaboration. All authors have read and approved the final manuscript.

\section{Author details}

${ }^{1}$ Department of Pharmacy, School of Pharmacy, University of Concepcion, Barrio Universitario S/N, Concepcion 3349001, Chile. ${ }^{2}$ Division of Occupational and Environmental Medicine, School of Medicine, University of Maryland, 11 South Paca Street, Suite 200, Baltimore, MD 21201, USA.

Received: 31 December 2015 Accepted: 31 March 2016

Published online: 08 April 2016

\section{References}

Acampora A, Castiglia L, Miraglia N, et al. A case study: surface contamination of cyclophosphamide due to working practices and cleaning procedures in two Italian hospitals. Ann Occup Hyg. 2005;49(7):611-8.

Berruyer M, Tanguay C, Caron N, et al. Multicenter study of environmental contamination with antineoplastic drugs in 36 Canadian hospitals: a 2013 follow-up study. J Occup Environ Hyg. 2015;12:87-94.

Bobin-Dubigeon C, Amiand M, Percheron C, et al. A new wipe-sampling prodecure coulped to LC-MS analysis for the simultaneous determination of 5-fluorouracil. Doxorubicin, and cyclophosphamide in surface contamination. J Anal Toxic. 2013;3(37):433-9.

Brouwers E, Huitema A, Bakker E, et al. Monitoring of platinum surface contamination in seven dutch hospital pharmacies using inductively coupled plasma mass spectrometry. Int Arch Occup Environ Health. 2007;80:689-99.

Castiglia L, Miraglia N, Pieri M, et al. evaluation of occupational exposure to antiblastic drugs in an Italian hospital oncological department. J Occup Health. 2008;50:48-56.

Connor T, DeBord G, Pretty J, et al. Evaluation of antineoplastic drug exposure of health care workers at three university-based US cancer centers. J of Occup \& Environ Medicine. 2012;52(10):1019-27.

Connor T, McDiarmid M. Preventing occupational exposures to antineoplastic drugs in health care settings. CA Cancer J Clin. 2006;56:354-65.

Davis J, McLauchlan R, Connor T. Exposure to hazardous drugs in healthcare: an issue that will not go away. J Oncol Pharm Practice. 2011;17(1):9-13.

De Jonge M, Van Dam S, Hillebrand $M$, et al. Simultaneous quantification of cyclophosphamide, 4-hydroxicyclophosphamide, $N, N^{\prime}, N^{\prime \prime}$ triethylenethiophosphoramide and $N, N^{\prime} N^{\prime \prime}$-triethylphosphoramide in human plasma by high-performance liquid chromatography coupled with electro spray ionization tandem mass spectrometry. J Mass Spectrom. 2004;39:262-71.

Fabrizi G, Fioretti M, Rocca L, et al. DESI-MS2: a rapid and innovative method for trace analysis of six cytostatic drugs in health care setting. Anal Bioanal Chem. 2012;403:973-83.
FDA Guidance for Industry, Bioanalytical Method Validation, 2001. http://www. fda.gov/downloads/Drugs/.../Guidances/ucm070107.pdf (accessed on December 2015).

Floridia L, Pietropaolo A, Tavazzani M, et al. High performance liquid chromatography of methotrexate for environmental monitoring of surface contamination in hospital departments and assessment of occupational exposure. J Chromatogr, B. 1999;726:95-103.

Friese C, McArdle C, Zhoo T, et al. Antineoplastic drug exposure in an ambulatory setting. Cancer Nurs. 2015;38(2):111-7.

Guillemette A, Langlois H, Voisine $\mathrm{M}$, et al. Impact and appreciation of two methods aiming at reducing hazardous drug environmental contamination: the centralization of the priming of IV tubing in the pharmacy and use of a closed-system transfer device. J Oncol Pharm Practice. 2014;20(6):426-32.

Hedmer M, Wholfart G. Hygienic guidance values for wipe sampling of antineoplastic drugs in Swedish hospitals. J Environ Monit. 2012;14:1968-75

Hedmer M, Georgiadi A, Ramme-Bremberg E, et al. Surface contamination of cyclophosphamide packing and surface contamination with antineoplastic drugs in a hospital pharmacy in Sweden. Ann Occup Hyg. 2005:49(7):629-37.

International Agency for Research on Cancer Monographs. Classification of carcinogens. 2015. http://monographs.iarc.fr/ENG/Classification/. Accessed on 7 December 2015.

International Conference on Harmonization of Technical Requirements for Registration of pharmaceuticals for Human Use: Validation on Analytical Procedures, Text and Methodology, Q2(R1), 1996. http://www.ich.org/ fileadmin/Public_Web_Site/ICH_Products/Guidelines/Quality/Q2_R1/Step4/ Q2_R1_Guideline.pdf. Accessed July 2015.

Kiffmeyer T, Tuerk J, Hahn M. Application and assessment of a regular environmental monitoring of the antineoplastic drug contamination level in pharmacies — the MEWIP project. Ann Occup Hyg. 2013;57(4):444-55.

Kopp B, Schierl R, Nowak D. Evaluation of working practices and surface contamination with antineoplastic drugs in outpatient oncology health care settings. Int Arch Occup Environ Health. 2013;86:47-55.

Larson R, Khazaeli M, Dillon K. Monitoring method for surface contamination caused by selected antineoplastic agents. Am J Health-Syst Pharm. 2002;59:270-7.

Larson R, Khazaeli M, Dillon H. Development of an HPLC method for simultaneous analysis of five antineoplastic agents. Appl Occup Environ Hyg. 2003;18(2):109-19.

Maeda S, Miwa Y. Multicomponent high-performance liquid chromatography/ tandem mass spectrometry analysis of ten chemotherapeutic drugs in wipe samples. J Chromatogr, B. 2013;921-922:43-8.

McDiarmid M, Oliver M, Roth T, et al. Chromosome 5 and 7 abnormalities in oncology personnel handling anticancer drugs. J Occup Environ Medicine. 2010;52(10):1028-34

NIOSH Alert. Preventing occupational exposures to antineoplastic and other hazardous drugs in health care settings, Department of Health and Human Services, Centers for Disease Control and Prevention, National Institute for Occupational Safety and Health, 2004.

Nussbaumer S, Geiser L, Sadeghipour F, et al. Wipe sampling procedure coupled to LC-MS/MS analysis for the simultaneous determination of 10 cytotoxic drugs on different surfaces. Anal Bioanal Chem. 2011;402(2):2499-509.

OSHA Directorate of Technical Support. Controlling occupational exposure to hazardous drugs. Instruction TED 1.15, September 1995.

OSHA Directorate of Technical Support. Controlling occupational exposure to hazardous drugs. Instruction TED 1.15, January 1999.

OSHA Guidelines for cytotoxic drugs. Publication No 8-1.1, January 1986

Pampal R, Bains T, Vaillancourt R, et al. Occupational exposure to cyclophosphamide in nurses at a single center. J of Occup \& Environ Medicine. 2014;56:304-12.

Pretty J, Connor T, Spasojevic I, et al. Sampling and mass spectrometric analytical methods for five antineoplastic drugs in the healthcare environment. J Oncol Pharm Practice. 2010;18(1):23-36.

Sabattini L, Barbieri A, Tosi M, et al. A new high-performance liquid chromatographic/electro spray ionization tandem mass spectrometric method for the simultaneous determination of cyclophosphamide, methotrexate and 5-fluorouracil as markers of surface contamination for occupational exposure monitoring. J Mass Spectrom. 2005;40:669-74.

Smith J, Sammons D, Robertson S, et al. Detection and measurement of surface contamination by multiple antineoplastic drugs using multiplex bead assay. J. Oncol. Pharm. Practice 2014; (Epub ahead of print). doi: 10. $1177 / 1078155214554407$.

Sottani C, Turci R, Schierl R, et al. Simultaneous determination of gemcitabine, taxol, cyclophosphamide and ifosfamide in wipe samples by high 
performance liquid chromatography tandem mass spectrometry: protocol of validation and uncertainty of measurement. Rapid Commun Mass Spectrom. 2007;21:1289-96.

Turci R, Sottani C, Spagnoli G, et al. Biological and environmental monitoring of hospital personnel exposed to antineoplastic agents: a review of analytical methods. J Chromatogr, B. 2003;789:169-209.

World Health Organization/Pan American Health Organization. Safe handling of hazardous chemotherapy drugs in limited-resource settings. 2013. Washington D.C. U.S.A. ISBN 978-92-75-11801-6.

Zeedijk M, Greijdanus B, Steenstra F, et al. Monitoring exposure of cytostatics on the hospital ward, measuring surface contamination of four different cytostatic drugs from one wipe sample. The Eur J Hosp Pharm Science. 2005;1:18-22.

\section{Submit your manuscript to a SpringerOpen ${ }^{\odot}$ journal and benefit from:}

- Convenient online submission

- Rigorous peer review

- Immediate publication on acceptance

- Open access: articles freely available online

- High visibility within the field

- Retaining the copyright to your article

Submit your next manuscript at $\gg$ springeropen.com 